\title{
Usage Pattern of Medical Information through the ClinicalKey Database among Medical Professionals of the Postgraduate Institute of Medicine
}

Chandima Wadasinghe ${ }^{1}$ and M.P.P. Dilhani ${ }^{2}$

\begin{abstract}
The rapid proliferation of medical information in the present era has important implications for patient care, patient education, and health professionals' research. This research examines the medical information usage pattern through the ClinicalKey database of medical professionals at the Postgraduate Institute of Medicine (PGIM), Sri Lanka. The study was conducted from June 2019 to June 2021 in the postgraduate trainers and trainees of PGIM. The method used has been based on the access of medical facts available in the ClinicalKey database and a survey conducted on the usage patterns of trainers and trainees of PGIM. The results showed a growing interest in ClinicalKey among the medical professionals at PGIM. The survey showed that the majority of respondents are MD trainees. The major purpose of using resources in

\footnotetext{
${ }^{1}$ Senior Assistant Librarian, Postgraduate Institute of Medicine, University of Colombo Email: chandima@pgim.cmb.ac.lk iD https://orcid.org/0000-0003-2384-1489

${ }^{2}$ Senior Assistant Librarian, Postgraduate Institute of Medicine, University of Colombo Email: dilhani@pgim.cmb.ac.lk iD https://orcid.org/0000-0002-8351-6568
} 
ClinicalKey as indicated by the users is for updating knowledge, patient care, diagnosis and treatment. Many medical professionals use the ebook: Principles and Practice of Infectious Diseases by Mandell, Douglas, and Bennett ( $9^{\text {th }}$ edition) and uses the journal, Surgery (Oxford). According to the keywords, 'surgery' is highly searched for research needs and education purposes. The study shows that medical professionals use e-resources often and spend more time on them. It is found that they use e-resources most frequently at home (48.40\%). that medical professionals mostly use laptops to access e-resources of ClinicalKey, followed by tablets. Among satisfaction levels with medical information, $71.4 \%$ of the medical professionals were happy with the ClinicalKey e-resources. $14.3 \%$ of medical professionals suggested an orientation program regarding the ClinicalKey database.

Keywords: E-resources, ClinicalKey, Usage Pattern, Medical Professionals, Medical Information, Online Database, InformationSeeking Behaviour 


\section{Introduction}

The invention of the internet has brought in an unprecedented use of e-resources for research and development in recent years compared to the diminishing use of print resources. Usage of the library by medical professionals is an essential means of enhancing their knowledge and self-directed learning skills. Information technology has affected the information-seeking behaviour of information users. Medical professionals utilise information sources such as medical databases to meet their diverse needs and to acquire up-to-date information. Williams (1992) categorised the information needs of health professionals, for example, confirming or disconfirming existing knowledge, assisting in solving a new or unfamiliar health care problem, and updating basic knowledge on a topic through review. Also, to get information from another speciality when dealing with a patient or person with multiple problems and to highlight patient care concerns to other health care team members. Further, it includes finding out about a rare or unusual patient care problem and determining whether a knowledge gap exists in the literature and whether a new research project or publication should be planned and assisting in implementing new administrative or organisational initiatives.

Medical information carries very high importance in any nation as its status determines the level of wellbeing of the people in a country (Institute of Medicine, 2003). Therefore, providing quality medical information is the duty of any government and institution dealing with medical training. This study may be more critical in postgraduate training as trainees use such information in their decision making - ensuring patient safety and quality of care - as well as in their professional 
development. Therefore, fulfilling information needs is essential for postgraduate medical professionals to perform their professional duties efficiently and effectively. At the same time, it is also necessary that medical professionals be skilful in gathering relevant information using appropriate resources. Therefore, postgraduate training institutions in medical education should understand the importance of utilisation of electronic medical databases efficiently to fulfil the information needs. Electronic knowledge resources have been defined as electronic (computer-based) resources comprising distilled (synthesised) or curated information that allows clinicians to select content pertaining to a specific patient to facilitate medical decision making ( $\underline{\text { Aakre, }}$ 2018).

This study provides data on the effective utilisation of medical information e-resources by the postgraduate medical trainees and trainers of the PGIM, University of Colombo: with reference to the ClinicalKey database. ClinicalKey is an online search engine launched by Elsevier in April 2012, and it is one of the most significant, most comprehensive products currently available for finding clinical medical information. Moreover, it provides an insight into clinical information that addresses essential clinical research requirements of physicians, medical librarians, and healthcare professionals. Also, it draws answers from the most extensive collection of clinical resources, covering every medical and surgical speciality (Wadasinghe, 2020). ClinicalKey offers 1362 full-text medical and surgical e-books and access to 862 full-text medical and surgical journals from the Elsevier collection and the Clinics of North America and has 11,200 practise guidelines and more than 2,600 drug monographs. It provides two types of multimedia access to 5,726,614 images and medical and surgical videos from books and journals. 
ClinicalKey offers more than 15,000 patient education handouts provided by the American Academy of Family Physicians, Elsevier Gold Standard, Ferri's Netter Patient Advisor, and Interactive Patient Education (Elsevier, 2021).

A medical practitioner must be capable of diagnosing and curing patients' diseases. Medical information must be accessible, authorised, reliable, accurate and timely. There is a dire need for a solid information system for health care professionals to meet the diverse information needs to perform their professional duties effectively and efficiently. Information about information usage patterns and information-seeking processes is essential in this regard. This study attempts to address this need of medical professionals at the Postgraduate Institute of Medicine, University of Colombo.

\section{Statement of Problem}

Library of the PGIM of Sri Lanka purchased the ClinicalKey database in 2019 to meet the information needs of present and future medical professionals. There has been no detailed study conducted so far to measure the use of e-resources of the ClinicalKey database and to assess factors that may influence the usage of these resources. Therefore, an inquiry is necessary to explore the usage of e-resources in the PGIM and the barriers that affect the effective use of these vital resources.

\section{Scope of the Study}

The scope of the study is to identify the medical information usage pattern by medical professionals in PGIM and to use its analysis to understand the impact of the medical information usage pattern of the 
PGIM library. Decision-makers can use the retrieved data of the study during the planning and setting of various strategies to promote the utilisation of electronic resources in the Postgraduate Institute of Medicine and other medical institutes.

\section{The Objective of the Study}

ClinicalKey is a reliable search engine and, it is an essential database for medical and surgical information. The main objective of this study was to explore and determine the ClinicalKey medical information usage pattern of medical professionals in PGIM. The objectives of this study are given below.

- To determine the information usage patterns of medical professionals on ClinicalKey

- To investigate the medical information resources used by medical professionals on ClinicalKey

- To assess the level of satisfaction with ClinicalKey

\section{Review of Literature}

The utilisation of information technology to obtain medical eresources has changed the information-seeking behaviour of PGIM medical professionals across the island over the last decade. The medical professionals utilise electronic medical resources to fulfil formal academic requirements and upgrade their knowledge for continuous professional development and patient care decision-making. Also, Medical information databases and electronic resources are the crucial resources that provide medical professionals with valid and up to date scientific information. According to Callen (2008), doctors are at the 
forefront of utilising modern information technologies for acquiring upto-date information. Multiple studies have been conducted to explore the effective utilisation of medical information e-resources by medical practitioners. The medical database tools help the health care professionals to make better-informed clinical decisions in a short period resulting in more accurate diagnosis and more effective treatment of the patient (Patel, 2015). Asemi \& Reyahiniya (2007) also confirmed that most users are well aware of digital resources available in the library. The study highlights users are faced with problems like low-speed connectivity and shortage of hardware facilities. Moretti (2012) has surveyed access to health information on the internet and related to the public health issue. This study aims to understand the user profile and search trends for health information on the internet. This study confirmed that the internet is a significant source of health information to improve data quality and promote public health. A systematic review and metaanalysis revealed that electronic information resources were associated with higher success in answering clinical questions than alternative resources, with varying effects on speed.

When comparing different implementation options for the same electronic knowledge resource, it appears that allowing physicians to choose how they want to access the resource versus an automatic display of resource information and incorporating patient-specific data have advantages (Maggio, 2019). Studies indicate that future enhancements should include university-wide online access to reputed journals and other key resources, improved computers with fast connectivity, information literacy training programs, and continued literature search sessions are key to practicing evidence-based medicine (Perera, 2015 \& 
Korukire, 2018). The literature further identified some of the factors affecting the utilisation of e-resources such as lack of awareness about electronic resources available in the library, insufficient IT equipment, lack of continuous training, high cost of resources, low-speed connectivity, quality of bandwidth internet, lack of time, workloads or too tight work schedules and a distinct preference for asking an expert colleague or consulting a print source had been reported as barriers to the use of online bibliographic databases (Kwadzo, 2015; Ehioghae, 2020 \& Alison, 2012). Also, a few studies identified that lack of quick and easy access to information, lack of access to EBM tool and lack of skills to identify and filter the useful information as a barriers to search reliable literature for clinical decisions, safe patient care and continuous professional development. (Phua, 2007 \& Nwafor-orizu, 2015). The information needs of health professionals stem from various factors, including patient care, patient education, professional curiosity, and research. The type of information used by health professionals depends on several factors, including the topic or issue in question, the knowledge base of the health professional, their knowledge of information sources, and the purpose for which the information will be used.

\section{Methodology}

The trainers, trainees, examiners, academic and library staff of the PGIM have been given access to the ClinicalKey database for academic purposes through the PGIM domain email. All those registered users utilise the ClinicalKey database as remote access. The total number of 2,043 users are registered with the ClinicalKey database for the period of 2019 June to 2021 June. The main source from which the information 
was gathered was the e-resources of the ClinicalKey database. In addition, all the medical professionals registered with the database were selected as the sample. Except for the library staff, $0.3 \%(n=6)$, information was collected from all medical professionals registered with the ClinicalKey database during the survey period. Accordingly, trainers (academic staff of the PGIM) and examiners 34.3\% ( $\mathrm{n}=701)$ and trainees $65.4 \%(n=1336)$ were selected for the sample, respectively.

An online self-administered structured questionnaire with openended and closed questions was used to collect data regarding usability, accessibility, and the credibility of the ClinicalKey database for making clinical decisions. The questionnaire was designed and piloted with 12 medical professionals before being administered using an online Google form for participants with internet access. After conducting a comprehensive review of the literature, the-questionnaire was designed. It was a well-structured questionnaire used as a tool for data collection, and collected data were analysed using SPSS statistical software.

\section{Results and Discussion}

The collected data from the ClinicalKey database and questionnaire was evaluated and interpreted, and the same is presented in the following tables and figures. Analysis of information is the decisive stride in the research process. It is the link between data and significant results leading to conclusions. With ClinicalKey, medical professionals can access the latest evidence across specialities in a variety of tools. 


\section{Performance Metrics of Registered Users}

The performance metrics of month-wise registered users in the ClinicalKey database for the period 2019 to 2021 is shown in Table 1 and Figure 1.

\section{Table 1}

Month-wise registered users

\begin{tabular}{lcc}
\hline Month/Year & Registered User & $\boldsymbol{\%}$ \\
\hline Jun-19 & 13 & 0.64 \\
Jul-19 & 21 & 1.03 \\
Aug-19 & 23 & 1.13 \\
Sep-19 & 27 & 1.32 \\
Oct-19 & 38 & 1.86 \\
Nov-19 & 43 & 2.10 \\
Dec-19 & 90 & 4.41 \\
Jan-20 & 58 & 2.84 \\
Feb-20 & 60 & 2.94 \\
Mar-20 & 62 & 3.03 \\
Apr-20 & 93 & 4.55 \\
May-20 & 109 & 5.34 \\
Jun-20 & 106 & 5.19 \\
Jul-20 & 90 & 4.41 \\
Aug-20 & 85 & 4.16 \\
Sep-20 & 93 & 4.55 \\
Oct-20 & 115 & 5.63 \\
Nov-20 & 111 & 5.43 \\
Dec-20 & 101 & 4.94 \\
& &
\end{tabular}


Journal of the University Librarians Association of Sri Lanka, Vol. 25, Issue 1, January 2022, 130, http://doi.org/10.4038/jula.v25i1.8051

\begin{tabular}{lcl} 
Jan-21 & 120 & 5.87 \\
Feb-21 & 103 & 5.04 \\
Mar-21 & 127 & 6.22 \\
Apr-21 & 123 & 6.02 \\
May-21 & 121 & 5.92 \\
Jun-21 & 111 & 5.43 \\
\hline Total & 2043 & 100 \\
\hline
\end{tabular}

According to the month-wise registered users, the lowest number of registered users are found in June 2019 (0.64\%), and the highest number of registered users are found in March 2021 (6.22\%).

\section{Figure 1}

Registered user count

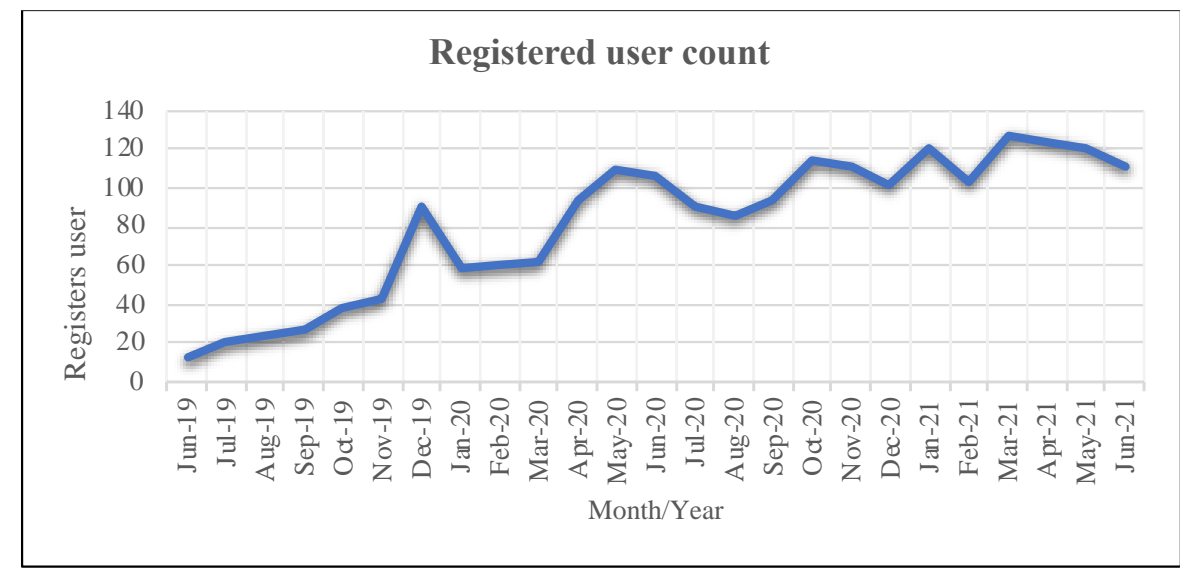

\section{Category Wise Data of the Registered Users}

Figure 2 shows collected data from different medical professionals, namely MD trainees $43.1 \%(\mathrm{n}=881)$, Trainers and Examiners 34.3\%(n=701), MSc Trainees 13.1\%(n=267), Diploma 
Trainees $9.2 \%(\mathrm{n}=188)$ and other $0.3 \%(\mathrm{n}=6)$, respectively. Most MD trainees are using the ClinicalKey.

\section{Figure 2}

Category wise data of the medical professionals

\section{Number of users}

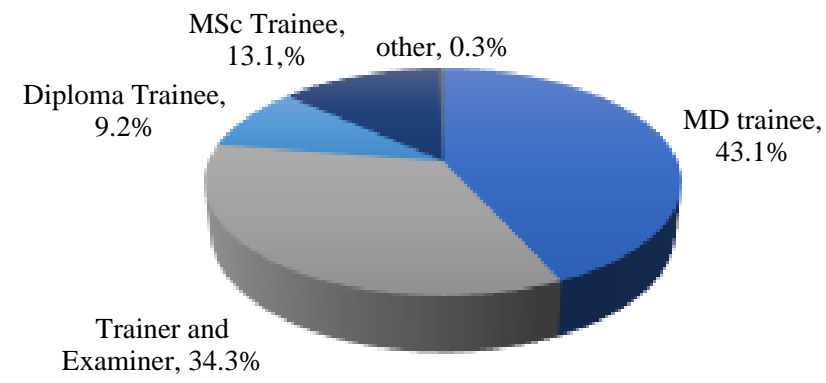

MD trainee Trainer and Examiner Diploma Trainee MSc Trainee other

\section{Usage Pattern of e-books}

ClinicalKey provides more than 1,000 full text medical and surgical e-books. Table 2 presents the top 25 most frequently retrieved ebooks on ClinicalKey from June 2019 to June 2021. Principles and Practice of Infectious Diseases (Ninth edition) by Mandell, Douglas, and Bennett's has 'the highest frequency.

\section{Table 2}

Top 25 e-Books used in Clinicalkey database

\section{Title}

Mandell, Douglas, and Bennett's Principles and Practice of

Infectious Diseases (Ninth edition)

Nelson Textbook of Pediatrics (Twenty-first edition)

\section{Frequency}

858 
Goldman-Cecil Medicine (Twenty-sixth Edition)

Campbell-Walsh Urology (Twelfth Edition)

Rosai and Ackerman's Surgical Pathology (Eleventh Edition) 612

Medical Microbiology (Nineteenth Edition) 608

Rosen's Emergency Medicine: Concepts and Clinical Practice 601

(Ninth Edition)

Braunwald's Heart Disease: a Textbook of Cardiovascular Medicine (Eleventh Edition)

Henry's Clinical Diagnosis and Management by Laboratory

Methods (Twenty-third Edition)

Current Surgical Therapy (Thirteenth Edition)

Miller's Anesthesia (Ninth Edition)

Plastic Surgery (Fourth Edition)

Comprehensive Clinical Nephrology (Sixth Edition)

Abdominal Imaging (Second Edition)

Cummings Otolaryngology (Seventh Edition)

Sleisenger and Fordtran's Gastrointestinal and Liver Disease

(Eleventh Edition)

Robbins \& Cotran Pathologic Basis of Disease (Tenth Edition)

Kumar and Clark's Clinical Medicine (Tenth Edition)

Sabiston Textbook of Surgery (Twentieth Edition)

Bradley's Neurology in Clinical Practice (Seventh Edition) 356

Brenner and Rector's the Kidney (Eleventh Edition) 356

Dermatology (Fourth Edition)

Hematology (Seventh Edition) 251

Cummings Otolaryngology (Sixth Edition) 249

Underwood's Pathology: a Clinical Approach (Seventh Edition) 248 


\section{Usage Pattern of e-journals}

ClinicalKey provides more than 700 full text medical e- journals. Ranking of the top e-journals on the research output on usage patterns for the year 2019-2021 is given in Table 3. Surgery (Oxford) is the leading journal with a maximum frequency.

\section{Table 3}

Top 25 e-journals in Clinicalkey database

\begin{tabular}{lc}
\hline \multicolumn{1}{c}{ Title } & Frequency \\
\hline Surgery (Oxford) & 760 \\
Ferri's Clinical Advisor 2021 & 610 \\
Surgical Clinics of North America & 557 \\
Paediatrics and Child Health & 530 \\
BJA Education & 409 \\
Ferri's Clinical Advisor 2020 & 372 \\
Medicine & 366 \\
The Lancet & 310 \\
Anaesthesia \& Intensive Care Medicine & 299 \\
Journal of the American College of Cardiology & 235 \\
Conn's Current Therapy 2020 & 209 \\
American Journal of Obstetrics and Gynecology & 203 \\
American Family Physician & 202 \\
Emergency Medicine Clinics of North America & 195 \\
Obstetrics, Gynaecology \& Reproductive Medicine & 186 \\
Journal of the American Academy of Dermatology & 185 \\
The Lancet Infectious Diseases & 182 \\
Pediatric Clinics of North America & 181 \\
&
\end{tabular}


Journal of Oral and Maxillofacial Surgery 178

Best Practice \& Research Clinical Obstetrics \& Gynaecology 176

Patient Education - Exit Care 158

Clinics in Dermatology 157

Gastroenterology 156

International Journal of Oral and Maxillofacial Surgery 156

Endocrinology and Metabolism Clinics of North America 155

\section{Usage Pattern of Book Chapters and Journal Articles}

The count of registered medical professionals who actively logged into their accounts during the reporting periods were significant. Figure - 3 exhibits the month-wise usage of book chapters and articles for the respective years.

\section{Figure 3}

Usage pattern of Book chapters and journal articles

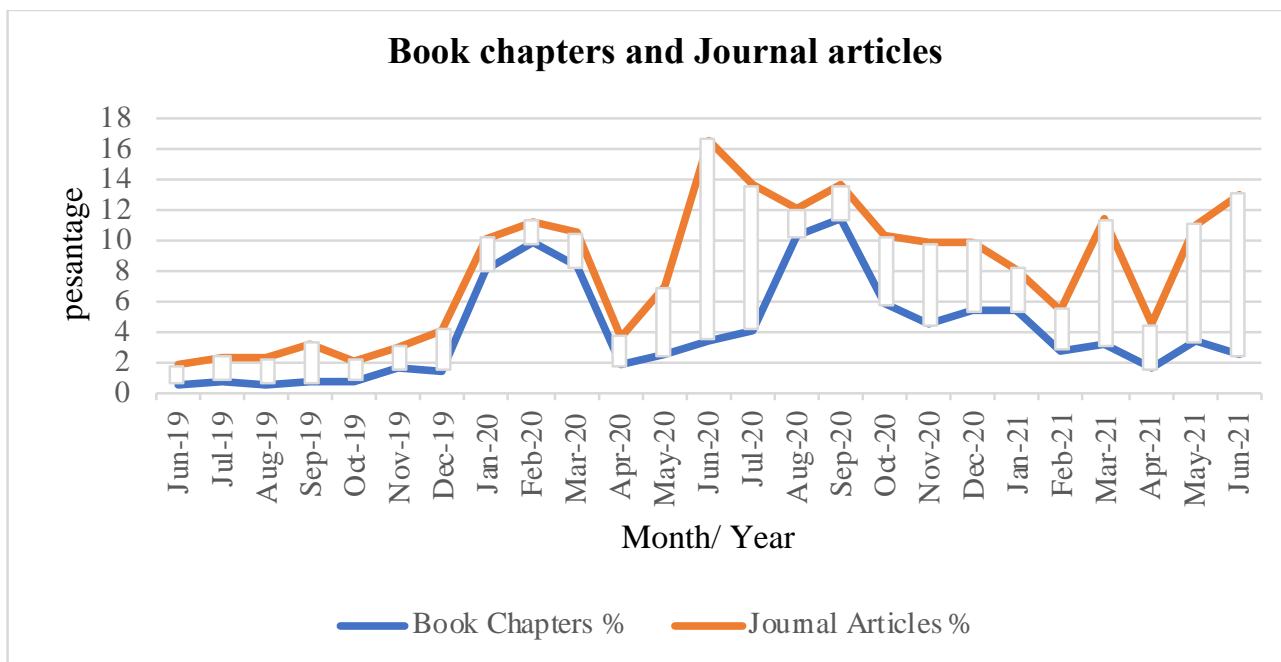


The medical professionals used a total count of 37,329 book chapters within the study period. This analysis showed that the most used number of book chapters were in September 2020 with 4,223 (11.31\%), August 2020 with 3,796 (10.17\%) and February 2020 with 3,648 (9.77\%) book chapters, each being published and ranked $1^{\text {st }}, 2^{\text {nd }}$ and $3^{\text {rd }}$ place in the period of study. According to the total number of users of journal articles $(23,877)$, the lowest number of users was found in June 2019 $(1.21 \%)$, and the highest number of users was found in June 2020 $(13.12 \%)$.

\section{Clinical Resources Tools}

Table 4 shows the usage pattern of clinical resources. Every user has access to clinical resources through different approaches. Most of the users $(23.67 \%)$ are much aware of comprehensive topic summaries for the clinical question (clinical overview), $14.84 \%$ of them looked for information to educate and empower the patient (patient education), $15.28 \%$ for image and video collection organised by speciality (multimedia), $15.95 \%$ are slightly aware of clinical trials experiments or observations done in clinical research (clinical trial), $14.14 \%$ of users looked for drug and dosing information to guide treatment decision (drug), followed by $8.15 \%$ being much aware of latest clinical guidelines from the leading organisation (guideline), and $7.97 \%$ were interested in quick videos to guide the procedure for best practice (procedure consults). 


\section{Table 4}

Usage pattern of clinical resources

\begin{tabular}{lrr}
\hline Clinical resources tools & Records & \% \\
\hline Clinical overview & 2826 & 23.67 \\
Patient education & 1772 & 14.84 \\
Multimedia & 1824 & 15.28 \\
Clinical trial & 1904 & 15.95 \\
Drug & 1688 & 14.14 \\
Guideline & 973 & 8.15 \\
Procedure consult & 951 & 7.97 \\
\hline Total & 11938 & 100 \\
\hline
\end{tabular}

\section{Usage Pattern of Different Information Resources}

Responses showed that the greatest number of respondents use book chapters for seeking information which is depicted in the following chart (Table 5).

\section{Table 5}

Usage Pattern of Different Information Resources

\begin{tabular}{lcccc}
\hline $\begin{array}{c}\text { Information } \\
\text { Sources }\end{array}$ & Mean & Median & Variance & $\begin{array}{c}\text { Standard } \\
\text { Deviation }\end{array}$ \\
\hline Book chapter & 1493.16 & 1180 & 1469832.06 & 1212.37 \\
Journal article & 955.08 & 632 & 603526.08 & 776.87 \\
Clinical overview & 113.04 & 101 & 1281.96 & 35.80 \\
Patient education & 70.88 & 72 & 98.78 & 9.94 \\
Multimedia & 72.96 & 74 & 166.46 & 12.90 \\
Clinical trial & 76.16 & 78 & 130.81 & 11.44
\end{tabular}




$\begin{array}{lcccc}\text { Drug } & 67.52 & 65 & 165.93 & 12.88 \\ \text { Guideline } & 38.92 & 41 & 51.58 & 7.18 \\ \text { Procedure consult } & 38.04 & 38 & 36.87 & 6.07\end{array}$

In the above table, the mean number of retrieving book chapters is 1493.16, whereas the variance is relatively very high, which means that the number of retrievals is broadly spread. In other words, the number of accurate retrievals in some months is enormously more elevated than the mean number of retrievals. The journal article having 955.08 as the mean, also shows the same spread pattern of retrievals as the table vehemently depicts. The other information resources show a spread pattern very close to the mean number of retrievals.

\section{Performance Metrics of the Content View}

Figure 4 shows the percentage of information searching view using Clinicalkey.

\section{Figure 4}

Content view

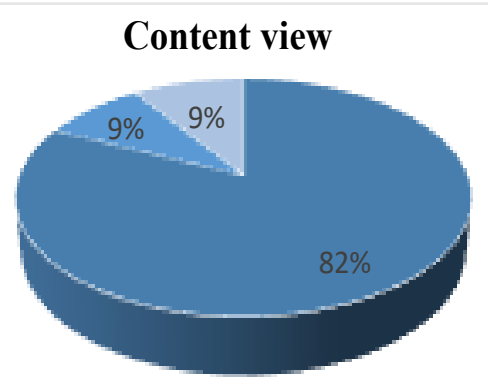

- Content view $\quad$ Topic Page Views $\approx$ Unique Content Titles Viewed 
Figure 4 reveals $82 \%$ of the content view that displays the most relevant content for each item. Furthermore, the total number of topic pages and unique content titles (it means the content is original and not duplicated anywhere else) display $9 \%$ each for the information searched by the medical professionals.

\section{Preference Level of Using e-resources}

Table 6 depict the preferred format for getting clinical resources information through ClinicalKey among the medical professionals. These resources are available as PDFs and can be added to presentation, emailed, and printed downloaded to read offline.

\section{Table 6}

Preference level of using e-resources

\begin{tabular}{lcc}
\hline Preference level & Record & \% \\
\hline PDF Downloads & 125216 & 93.51 \\
Content Prints & 7350 & 5.49 \\
Presentation Export & 1347 & 1.01 \\
Total & 133913 & 100
\end{tabular}

The above table shows the preferred format for downloading the article, printing and exporting it to presentations from the ClinicalKey database. The majority of medical professionals have used 125,216 (93.51\%) PDF format, 7,350 (5.49\%) content print, and 1,347 (1.01\%) presentation exports. Therefore, most users use PDF format instead of other formats. 


\section{Keywords of Unique Content Titles Viewed}

Highly productive keyword areas output for the study period of 2019 to 2021 found a total of 25 specialities.

Table 7 shows the top twenty-five high productive subject areas in research output in the ClinicalKey database. The keywords of unique content titles were viewed during 2019-2021 in the context of subject areas (as reflected in ClinicalKey database classification), with the highest keyword output coming from surgery, followed by general medicine and paediatrics. The lowest contribution of keywords among the top 25 list of keywords occupied in internal medicine publications.

\section{Table 7}

Keywords of unique content titles viewed

\begin{tabular}{lc}
\hline Keywords & $\begin{array}{c}\text { No of the content titles } \\
\text { viewed }\end{array}$ \\
\hline Surgery & 2716 \\
General medicine & 1909 \\
Paediatrics & 1635 \\
Emergency Medicine & 1580 \\
Pathology & 1534 \\
Anaesthesiology & 1439 \\
Neurology & 1433 \\
Microbiology & 1414 \\
Family medicine & 1396 \\
Endocrinology & 1393 \\
Cardiology & 1390 \\
Dermatology & 1313
\end{tabular}


Pharmacology and Therapeutics 1289

Rheumatology 1278

Psychiatry 1275

Obstetrics and Gynaecology 1269

Forensic Medicine 1268

Orthodontics 1264

Anatomy 1254

Nutrition 1244

Histopathology 1241

Dentistry 1187

Internal Medicine 1174

Parasitology 1153

Disaster Management 1151

\section{Purpose of Using e-resources of ClinicalKey}

Medical information helps medical professionals with decisions and actions. It enhances patient care by making it more efficient while the patient records and medical knowledge are captured, processed, communicated, and applied (Wyatt \& Sullivan, 2005).

The study sought to determine the purposes of using electronic resources by trainers, trainees and academics attached to the PGIM. To obtain the answers, the respondents were asked to indicate their purposes of using ClinicalKey in their respective locations, as outlined in the figure below. 


\section{Figure 5}

Purpose of using e-resources of ClinicalKey

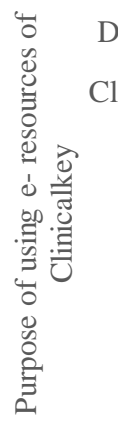

Diagnosis and treatment

Clinical decision making

Patient care

Up-to-date knowledge

Medical research

Teaching

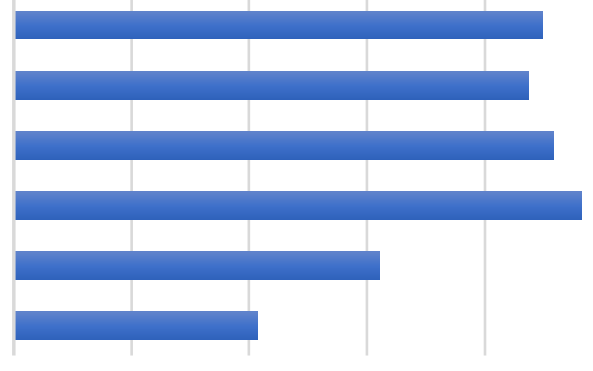

$0 \quad 20$

40

60

80

100

Figure 5 above presents the information on the purpose for using resources in ClinicalKey by users. For up-to-date knowledge (96.4\%) was ranked highest as the main purpose for using resources in Clinicalkey and was followed by patient care (91.7\%), diagnosis and treatment $(89.8 \%)$, clinical decision making (87.75\%), medical research $(62.2 \%)$ and teaching $(41.34 \%)$ respectively.

\section{Frequency of Using e-resources}

Medical professionals were requested to mark their frequency of the use of e-resource under one of the headings - very-often, often, sometimes, and rarely (Figure 6) to determine the frequency of use of eresources of ClinicalKey. Regarding the frequency of using e-resources, the respondents have reacted differently. Figure 6 shows that $44.4 \%$ of medical professionals use Clinicalkey e-resources often, $38.9 \%$ use these sometimes, and $8.4 \%$ very often.8.3\% of medical professionals use eresources rarely. 


\section{Figure 6}

Frequency of the use of e-resources of ClinicalKey

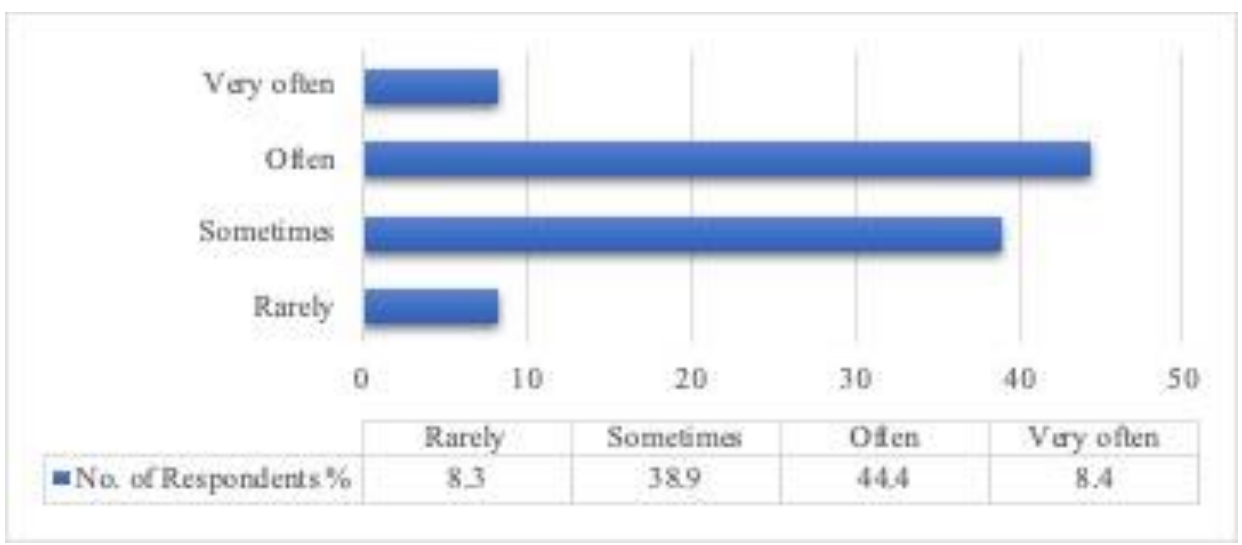

\section{Location of Accessing of ClinicalKey e-resources}

Medical professionals were requested to mention their most convenient location or using ClinicalKey e-resources (Figure 7).

\section{Figure 7}

Place of accessing ClinicalKey

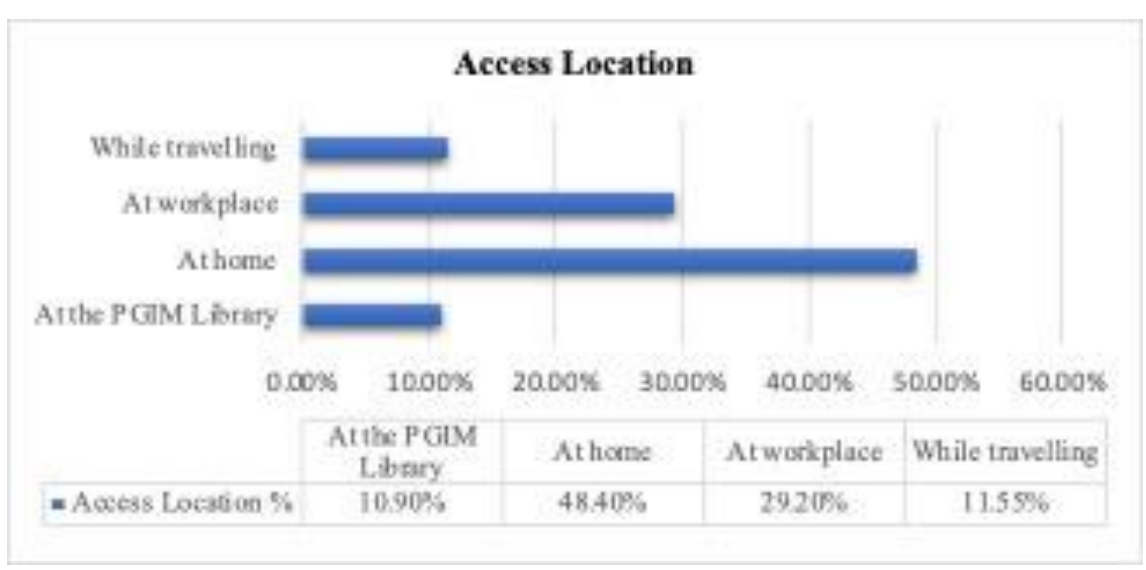

The place of accessing e-resources of ClinicalKey by medical professionals is mostly from home $(48.40 \%, \mathrm{n}=985)$. It was followed by 
the number of accesses at the workplace with $29.20 \%(n=595)$. While $11.55 \%(\mathrm{n}=235)$ use and access e-resources while travelling and $10.9 \%(n=222)$ use the e-resources at the library of the PGIM.

\section{Usage of Devices to Access}

The chart below depicts the preference for comfortable handling of the devices by medical professionals.

\section{Figure 8}

Usage of devices to access the e-resources of ClinicalKey

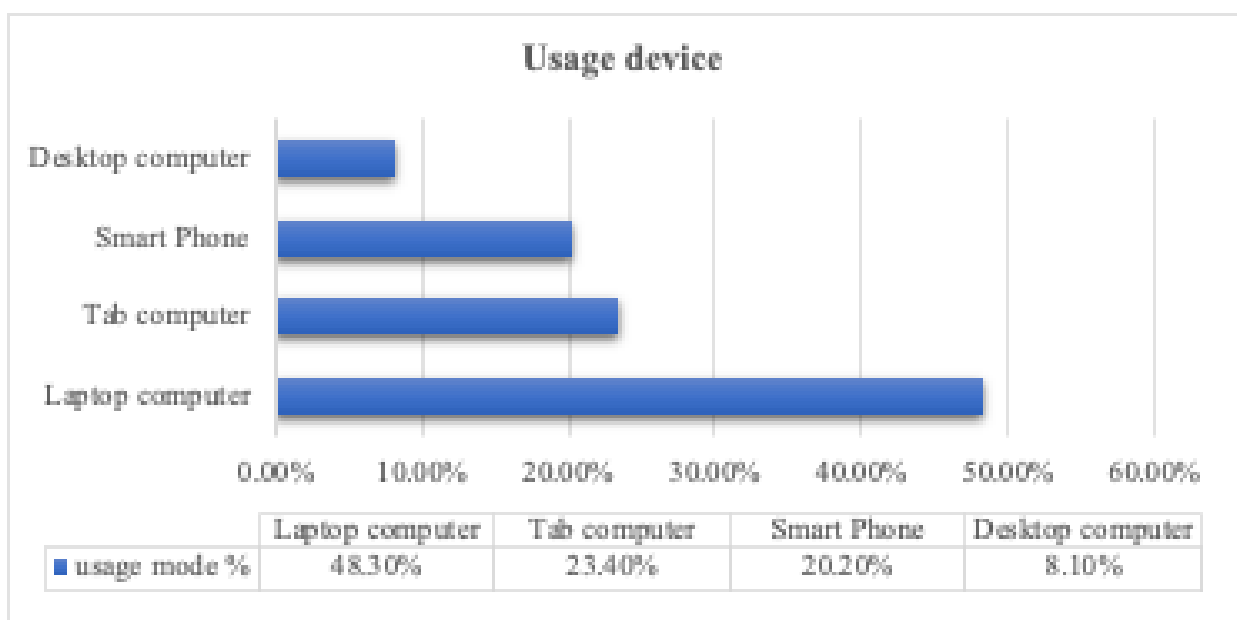

The most used devices to access ClinicalKey e-resources are laptop computers followed by tab computers. Use of smart phone is $20.2 \%$ and desktop computer $8.1 \%$.

\section{Level of Satisfaction with ClinicalKey e-resources}

Figure 9 analysed satisfaction on e-resources in ClinicalKey among the medical professionals. On analysing the satisfaction level of 
medical professionals with e-resources for retrieving the required information, most of the medical professionals were satisfied with their effectiveness in answering specific clinical questions (74.5\%), followed by $73.3 \%$ with the ease-of-use whereas $71.4 \%$ for overall satisfaction with ClinicalKey database. Above figure 9 shows that $63.2 \%$ are satisfied with the quality of the answer that was found, and 59.8\% are happy with the quality of their solution. Followed by $56.6 \%$ being pleased with the usefulness of instructions and $51.7 \%$ being satisfied with userfriendliness.

\section{Figure 9}

Level of satisfaction with ClinicalKey resources

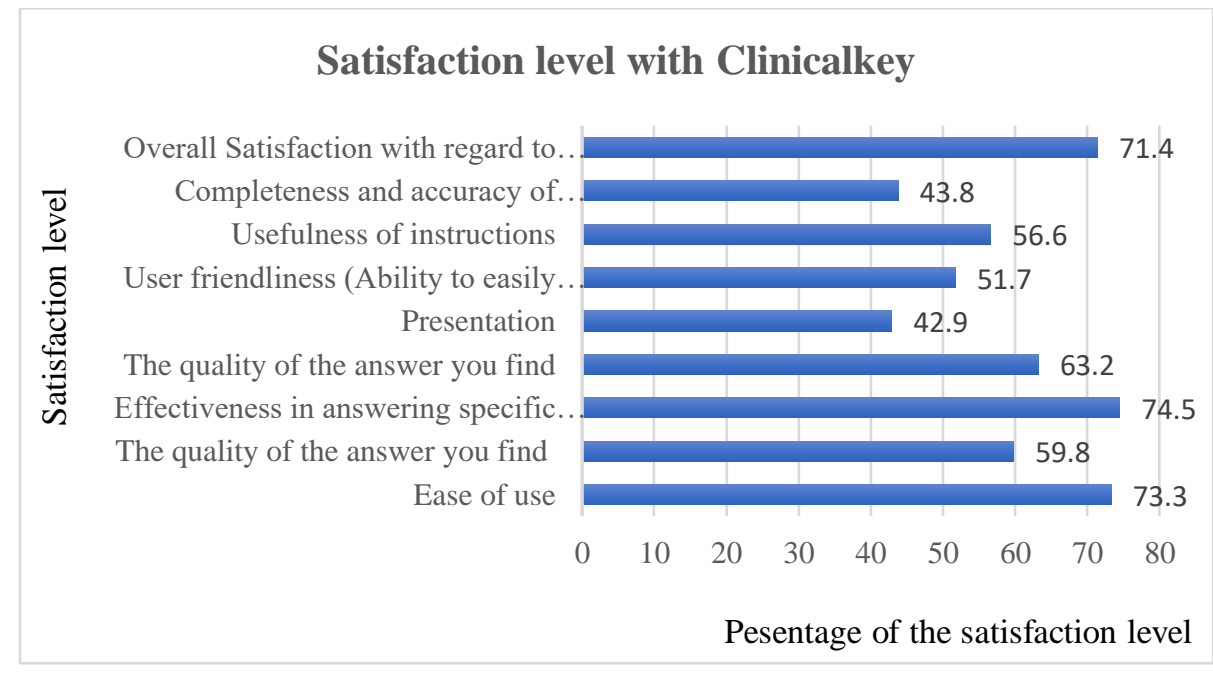

Concerning completeness and accuracy of instructions, $43.8 \%$ are satisfied, and $42.9 \%$ are satisfied with the presentation of the ClinicalKey. Hence, the above figure clearly shows that in the level of 
satisfaction with the ClinicalKey database, the majority of respondents are delighted with the medical information of the ClinicalKey.

\section{Conclusion}

Medical information is essential for medical professionals to diagnose and cure patients' diseases. There was a need for a solid information-system for health care professionals to meet the diverse information needs in performing their professional duties effectively and efficiently. The main objective of this study is to improve the provision of high-quality medical information to PGIM medical professionals. ClinicalKey database fulfils the medical professional's requirements of medical information. The study thus leads to examine the informationseeking behaviour of the users of PGIM and shows that they have a greater interest in ClinicalKey database provided by PGIM. Medical information is an important commodity in every aspect of their profession. The Library of the PGIM is one of the medical information centres which facilitates the growth of professional careers of medical professionals as well as creating goodwill and healthy society. The proliferation of e-resources has a major impact on medical professionals' use and preserve medical information.

This study provides the pattern of usage of all registered medical professionals of ClinicalKey of PGIM from 2019 - 2021. All registered users have used the ClinicalKey database with remote access. The majority of them are delighted with ClinicalKey- resources and their ease of use and the effectiveness of answering specific clinical questions. It is observed that MD respondents mainly used e-resources. The survey results showed that postgraduate doctors preferred to use e-books and e- 
journals. ClinicalKey electronic resources impose a significant impact on medical professionals' use of medical information.

The analysis of the study shows that ClinicalKey electronic resources plays a vital part in medical information provision and are widely used by medical professionals of PGIM. It has an impact on the way of searching and disseminating information. It reveals that most medical professionals are aware of ClinicalKey e-resources and use this e-resource to search for medical information online. However, this finding showed that most of the respondents were using electronic databases purposely for research activities and thesis writing. Hence there is a dire need for effective user education, orientation programme, workshops, seminars etc. among the medical professionals of the PGIM so that they can get the maximum benefit from the e-resources of ClinicalKey.

The study concluded that ClinicalKey e-resources provide the opportunity to access the current and up-to-date data/information. These valuable information resources have been utilised by most of the medical professionals of the PGIM for better informed and updated medical knowledge.

\section{References}

Aakre, C. A., Pencille, L. J., Sorensen, K. J., Shellum, J. L., Del Fiol, G., Maggio, L. A., Prokop, L. J., \& Cook, D. A. (2018). Electronic

Knowledge Resources and Point-of-Care Learning: A Scoping

Review. Academic Medicine : Journal of the Association of American Medical Colleges, 93 (11S Association of American 
Medical Colleges Learn Serve Lead: Proceedings of the 57th Annual Research in Medical Education Sessions), S60-S67. https://doi.org/10.1097/ACM.0000000000002375

Alison, K. A., Kiyingi, G. W., \& Baziraake, B. B. (2012). Factors affecting utilisation of electronic health information resources in universities in Uganda. Annals of Library and Information Studies, 59(2), 90-96.

Asemi, A., \& Riyahiniya, N. (2007). Awareness and use of digital resources in the libraries of Isfahan University of Medical Sciences, Iran. Electronic Library, 25(3), 316-327. https://doi.org/10.1108/02640470710754823

Callen, J. L., Buyankhishig, B., \& McIntosh, J. H. (2008). Clinical information sources used by hospital doctors in Mongolia. International Journal of Medical Informatics, 77(4), 249-255. https://doi.org/10.1016/j.ijmedinf.2007.06.003

Ehioghae, M., \& Madukoma, E. (2020). Health Information Use by Resident Doctors in Lagos State University Teaching Hospital, Ikeja, Lagos State, Nigeria. Information Impact: Journal of Information and Knowledge Management, 11(3), 41-50. https://doi.org/10.4314/iijikm.v11i3.5

Elsevier. (2021). ClinicalKey. https://www.Clinicalkey.Com.

Institute of Medicine. (2003). Committee on Assuring the Health of the Public in the 21st Century. The future of the public's health in the $21^{\text {st }}$ century, 25 .

Korukire, N., Joseph Lune, N., Tuyizere, M., Nsereko, E., Basheija, D., \& Ineza, M. (2018). Utilization of online bibliographic databases by medical doctors in a teaching hospital in Rwanda. Rwanda Journal 
of Medicine and Health Sciences, 1(1), 15-21.

https://doi.org/10.4314/rjmhs.v1i1.3

Kwadzo, G. (2015). Awareness and usage of electronic databases by geography and resource development information studies graduate students in the University of Ghana. Library Philosophy and Practice (E-Journal), 1210. https://digitalcommons.unl.edu/cgi/viewcontent.cgi?article=3241\&c ontext=libphilprac

Maggio, L. A., Aakre, C. A., Del Fiol, G., Shellum, J., \& Cook, D. A. (2019). Impact of Clinicians' Use of Electronic Knowledge Resources on Clinical and Learning Outcomes: Systematic Review and Meta-Analysis. Journal of Medical Internet Research, 21(7), e13315. https://doi.org/10.2196/13315

Moretti, F. A., Oliveira, V. E. de, \& Silva, E. M. K. da. (2012). Access to health information on the internet: a public health issue? Revista Da Associacao Medica Brasileira (1992), 58(6), 650-658. https://doi.org/10.1590/s0104-42302012000600008

Nwafor-orizu, O. E., \& Onwudinjo, O. T. U. (2015). Barriers to Optimal Utilization of Health Information Resources by Doctors in Nigeria. 5(18), 1-8.

http://www.iiste.org/Journals/index.php/DCS/article/viewFile/25472 126410

Patel, R., Green, W., Shahzad, M. W., \& Larkin, C. (2015). Use of Mobile Clinical Decision Support Software by Junior Doctors at a UK Teaching Hospital: Identification and Evaluation of Barriers to Engagement. JMIR MHealth UHealth, 3(3), e80. https://doi.org/10.2196/mhealth.4388 
Perera, P. A. S. H. (2015). Preferences and Pattern of Information Seeking of Academics of Health-Related Faculties, University of Peradeniya (UoP). Journal of the University Librarians Association of Sri Lanka, 18(2), 61-75. https://doi.org/10.4038/jula.v18i2.7866

Phua, J., \& Lim, T. K. (2007). Use of traditional versus electronic medical information resources by residents andinterns. Medical Teacher, 29(4), 400-402. https://doi.org/10.1080/01421590701477456

Wadasinghe, C. (2020). Trends in e-literature on cardiovascular diseases: A bibliometric analysis with reference to ClinicalKey (2015 -2019). Sri Lanka Library Review, 34(2), 24-47. https://doi.org/10.4038/sllr.v34i2.32

Williams, R., Baker, L., Marshall, J., \& Thorofare, N. (1992). Information Searching in Health Care. Journal of Physical Therapy Education, Slack Inc.

Wyatt, J. C., \& Sullivan, F. (2005). What is health information? BMJ, 331(7516), 566. https://doi.org/10.1136/bmj.331.7516.566 